Check for updates

Belfast, UK

chrisbaraniuk@gmail.com Cite this as: BMJ 2021;374:n1960 http://dx.doi.org/10.1136/bmj.n1960 Published: 9 August 2021

\section{Covid-19: How effective are vaccines against the delta variant?}

\section{The delta variant is now the dominant form of SARS-CoV-2 in the UK and many other countries. Chris Baraniuk asks how effective the leading vaccines are against this new threat}

\section{Chris Baraniuk freelance journalist}

“Two days after my first symptoms, I began to feel seriously ill," wrote BBC TV presenter Andrew Marr. ${ }^{1}$ He described how he had previously felt invulnerable having received both of his covid vaccine doses. Nonetheless, he became infected with the virus, which he suspects he caught at the G7 summit in Cornwall.

Marr recovered but some have not. Data from Public Health England (PHE) reveal that of all the people who died within 28 days of testing positive for the delta variant between 1 February and 19 July, 49\% (224) had had two vaccine doses. Almost all of these people, 220, were aged 50 or older. ${ }^{2}$

As the statistician David Spiegelhalter notes, in a population where less-than-perfect vaccines have been distributed widely, one would expect to see deaths occurring among vaccinated people as the virus spreads. And so far, in contrast to the winter when far fewer people had received vaccines, the rate of hospital admissions and deaths in the UK is not rising as sharply as cases.

Although uncertainty remains, there is reason to be confident about the protection offered by current covid vaccines, says Eleanor Riley, professor of immunology and infectious disease at the University of Edinburgh. Referring to Marr, who had a major stroke in 2013, she says: "A man over 60 with significant prior health problems got a mild, flu-like illness and was back at work in a week."

\section{Warning signs}

Data up to 4 August from Imperial College London's React study found that people who said they had received two vaccine doses were half as likely to test positive for covid-19, adjusting for other factors such as age and whether or not they had symptoms. ${ }^{3}$ The researchers estimated a 50-60\% lower risk of infection from the delta variant if a person was double vaccinated.

The picture emerging from various countries does, however, suggest that vaccinated people are more likely to experience symptoms after catching the delta variant compared with earlier forms of the virus.

Data published by the Israeli government suggest that the Pfizer BioNTech jab's efficacy against symptomatic infection fell from $94 \%$ to $64 \%$ after the delta variant began spreading in the country. ${ }^{4}$

Figures from Public Health Scotland published in the Lancet also show a drop in protection against symptomatic illness, ${ }^{5}$ from $92 \%$ against the alpha variant, which was first detected in the UK, to $75 \%$ against delta among people with two doses of the Pfizer BioNTech vaccine. For the Oxford AstraZeneca vaccine, the reduction was from $81 \%$ to $61 \%$. Data from Canada, yet to be peer reviewed, also show a drop in efficacy. ${ }^{6}$

It's difficult to compare data from multiple countries because they all have different protocols determining when people become eligible for a covid-19 test, for example. And symptomatic infection can take many forms, from very mild to severe illness.

But Riley points out that the PHE data to date are consistent with estimates that suggest-despite these drops in efficacy - vaccines in use in the UK (Pfizer BioNtech, AstraZeneca, and Moderna) all reduce the risk of death by more than $85 \%$, regardless of variant.

What about transmission?
A lingering question is to what extent the vaccines may
be losing effectiveness at preventing onward
transmission from people who become infected. After
all, each of the new variants is characterised by increased
transmissibility compared with the original (wild type)
SARS-CoV-2.
Akiko Iwasaki of Yale University says we won't know
unless we can get more observational studies following
household contacts.
One yet to be peer reviewed study looked at a single
outdoor wedding near Houston, Texas, in April where all
92 guests were required to be fully vaccinated.7 ${ }^{7}$ couple
who had travelled from India later tested positive for
delta, with one dying a month later. Of the people they
interacted with at the wedding, four became ill with delta.
One required monoclonal antibody treatment, but all
four survived.
A recently released report from the US Centers for Disease
Control and Prevention suggests that the viral load of
vaccinated people infected with the delta variant is
similar to that of unvaccinated people. ${ }^{8}$ People remain
less likely to become infected in the first place when they
have been vaccinated, however.

\section{Neutralising antibodies}

It's not yet clear how the body's immune system fights SARS-CoV-2. Without knowing for sure what the correlates of protection are, it's hard to say why a vaccine may be less effective against variants. Evidence is accumulating, however, that the ability of antibodies to neutralise the delta variant is reduced compared with, say, the alpha variant.

A study published in Nature found that antibodies in blood samples (sera) from convalescent patients up to 12 months post-infection were four times less effective at neutralising the delta variant than the alpha variant. ${ }^{10}$ Sera from people who had only a single dose of the Pfizer BioNTech or Oxford AstraZeneca vaccines "barely" inhibited delta, wrote the authors. 
They did, however, see a neutralising response in sera from almost all people who had received two doses of a vaccine.

Another study on neutralising antibodies, published in the Lancet, found that, following two doses of the Oxford AstraZeneca vaccine, the number of people who had quantifiable antibodies against delta was significantly lower, at $62 \%$ (39 of 63), than against the original wild type SARS-CoV-2 (100\% of participants).

That may sound worrying, but Akiko Iwasaki, professor of immunobiology and molecular, cellular, and developmental biology at Yale University, says there is reason to be hopeful that people who have had two vaccine doses can still fend off severe disease when infected by delta. This is likely to be in part because of other aspects of the immune system, such as T cells that stimulate B cells to produce antibodies or killer $\mathrm{T}$ cells that destroy infected cells in the body. ${ }^{11}$

She also points out that a reduction in neutralising antibodies does not necessarily mean that antibodies will fail to have an impact. "I assume that the reason we can still prevent severe disease from the delta variant is that we are generating enough antibody response against the spike protein,” she says.

Laboratory based analysis of antibody and $\mathrm{T}$ cell responses to the original SARS-CoV-2 virus and multiple variants coauthored by Iwasaki and yet to be peer reviewed found that, against delta, vaccination still prompted neutralising antibodies. ${ }^{12}$ There were, however, more antibodies in people who had caught covid-19 before vaccination.

The bottom line is that delta-a variant with distinct mutations making it much more transmissible, blunting immune protection as much as 10-fold-poses a challenge to the vaccines currently used. But in most people the vaccine induced levels of neutralising antibodies are large enough that even a 10-fold drop keeps them well protected.

So, while it's sobering to see cases occurring in fully vaccinated people, their protection is holding up well, as judged by numbers of hospital admissions and fatalities relative to what might have been. As Iwasaki puts it: the message should still be to get vaccinated as soon as possible.

\footnotetext{
Manufacturers confident

"We haven't seen any evidence that the circulating variants result in a loss of protection provided by the Pfizer BioNTech covid-19 vaccine (BNT162b2) in our laboratory studies," a spokeswoman for Pfizer told The $B M$ J.

AstraZeneca said in a statement: "Real world data from Public Health Scotland published in the Lancet, reaffirmed the AstraZeneca covid-19 vaccine was effective in reducing the risk of SARS-CoV-2 infection and hospital admissions because of the delta variant but at a slightly lower level compared with the alpha variant."

Moderna has said tests show that its vaccine continued to produce neutralising activity against multiple variants of concern, including delta, ${ }^{13}$ while a Janssen spokesperson told The BMJ, "Against the emerging variants of concern, neutralising antibodies were higher against the delta variant than what was observed for the beta variant in South Africa."

Despite this universal confidence, however, Pfizer, for one, is at work on an updated version of its vaccine, targeting the delta variant specifically. The company hopes this will enter clinical studies in August.
}

Commissioned, externally peer reviewed

Competing interests: I have read and understood BMJ policy on declaration of interests and have no relevant interests to declare.
1 Marr A. Marr on catching Covid after being double vaccinated. 28 June 2021. www.bbc.co.uk/news/health-57640550.

2 Public Health England. Investigation of SARS-CoV-2 variants of concern: technical briefings. 23 July 2021. www.gov.uk/government/publications/investigation-of-novel-sars-cov-2-variant-variantof-concern-20201201.

3 Elliot P, Haw D, Wang H, et al. React-1 round 13 final report: exponential growth, high prevalence of SARS-CoV-2 and vaccine effectiveness associated with delta variant in England during May to July 2021. 4 August 2021. [Preprint] www.imperial.ac.uk/medicine/research-and-impact/groups/react-study/real-time-assessment-of-community-transmission-findings.

4 Odenheimer A, Shepherd D. Pfizer shot halts severe illness in Israel as delta spreads. Bloomberg. 5July 2021. www.bloomberg.com/news/articles/2021-07-05/israel-sees-decline-in-pfizer-vaccineefficacy-rate-ynet-says.

5 Sheikh A, McMenamin J, Taylor B, Robertson CPublic Health Scotland and the EAVE II Collaborators. SARS-CoV-2 Delta VOC in Scotland: demographics, risk of hospital admission, and vaccine effectiveness. Lancet 2021;397:2461-2. doi: 10.1016/S0140-6736(21)01358-1 pmid: 34139198

6 Nasreen S, He S, Chung H, etal. Effectiveness of covid-19 vaccines against variants of concern, Canada.Medrxiv2021.06.28.21259420 [Preprint]. 2021doi: 10.1101/2021.06.28.21259420.

7 Farinholt T, Doddapaneni H, Qin X, etal. Transmission event of SARS-CoV-2 delta variant reveals multiple vaccine breakthrough infections.medRxiv 2021.06.28.21258780. 2021doi: 10.1101/2021.06.28.21258780.

8 Brown CM, Vostock J, Johnson H, etal. Outbreak of SARS-CoV-2 infections, including covid-19 vaccine breakthrough infections, associated with large public gatherings: Barnstable County, Massachusetts, July 2021. MMWR2021. www.cdc.gov/mmwr/volumes/70/wr/mm7031e2.htm.

9 Alford J. Coronavirus infections three times lower in double vaccinated people - React. Imperial College London. 4 August 2021. www.imperial.ac.uk/news/227713/coronavirus-infections-threetimes-lower-double.

10 Planas D, Veyer D, Baidaliuk A, etal. Reduced sensitivity of SARS-CoV-2 variant Delta to antibody neutralization. Nature 2021. doi: 10.1038/s41586-021-03777-9. pmid: 34237773

11 Baraniuk C. How long does covid-19 immunity last?BMJ2021;373:n1605 doi: 10.1136/bmj.n1605 pmid: 34193457

12 Lucas C, Vogels CBF, Yildirim I, etal. Impact of circulating SARS-CoV-2 variants on mRNA vaccine-induced immunity in uninfected and previously infected individuals.medRxiv 2021.07.14.21260307 [Preprint]. 2021doi: 10.1101/2021.07.14.21260307.

13 Moderna provides a clinical update on the neutralizing activity of its covid-19 vaccine on emerging variants including the delta variant first identified in India. Moderna. 29 June 2021. https://investors.modernatx.com/news-releases/news-release-details/moderna-provides-clinical-updateneutralizing-activity-its-covid.

This article is made freely available for use in accordance with BMJ's website terms and conditions for the duration of the covid-19 pandemic or until otherwise determined by BMJ. You may use, download and print the article for any lawful, non-commercial purpose (including text and data mining) provided that all copyright notices and trade marks are retained. 